\title{
BM Global Heath Need for more and better implementation science in global health
}

\author{
Valéry Ridde ${ }^{1,2}$
}

To cite: Ridde V. Need for more and better implementation science in global health. BMJ Global Health 2016;1:e000115. doi:10.1136/bmjgh-2016000115

Received 23 June 2016 Revised 18 July 2016 Accepted 19 July 2016

\section{CrossMark}

\section{${ }^{1}$ Universite de Montreal, School of Public Health (ESPUM), Montreal, Quebec, Canada \\ ${ }^{2}$ Universite de Montreal Institut de recherche en sante publique (IRSPUM), Montreal, Quebec, Canada}

Correspondence to Professor Valéry Ridde; valery.ridde@umontreal.ca
'We know what we have to do, but we don't know how to do it' has been a recurring comment among global health actors for a long time. In 2010, for example, the United Nations affirmed that "we know what works"1 in taking care of the health of women and children. The WHO Commission on the Social Determinants of Health (2008) has highlighted effective interventions to improve the health of populations and to establish health equity. ${ }^{2}$ However, while the content of interventions, which are theoretically effective, are relatively well known, their level of coverage is weak. ${ }^{3}$ Furthermore, the conditions of their implementation are less understood. An old meta-analysis shows that the potential effectiveness of interventions is reduced by $50 \%$ because of multiple contextual factors which act against the implementation. ${ }^{4}$ Therefore, it is not enough to know if a health intervention is effective; it is also necessary to understand why the intervention works, how, for whom and in which contexts. It is here where implementation science is an undeniable aid.

In this editorial, the focus will not be on the controversies concerning the definition of implementation science or the academic arguments made in order to appropriate or better sell the training of implementation science. Essentially, what is of interest is to call on the community of students, researchers, implementers and donors to commit themselves to further and a better quality research in order to have a greater understanding of how to implement health interventions. To quote Joseph Durlak, an important author in this field, 'studying programme implementation is not easy but it is essential'. ${ }^{5}$ Implementation is comprised of one or several processes organised in a particular context so as to bring about the desired changes of an intervention (whether policy, programme or project) through the means necessary to deploy it. Implementation science is about mobilising theories, concepts and methods to better 'understand what, why, and how interventions work in 'real world' settings'. ${ }^{6}$ There is a movement away from implementation research, which is centred on analysing the way interventions consider evidence, a field that is close to knowledge transfer, which is also not fully developed in low and middle income countries (LMICs). ${ }^{7}$ However, we do agree with the fact that 'research in both fields deals with the challenges of translating intentions into desired changes'. ${ }^{8}$ A meeting of major journal editors has been organized by the Canadian Institutes of Health Research Institute of Population and Public Health and the Canadian Journal of Public Health in April 2016 (http://sparkingsolutions.ca). They will soon launch the Ottawa Statement to promote publications in the field of population health intervention research.

BMJ Global Health wishes to participate in the development of implementation science but with a focus on equity and on a better adaptation and/or creation of theoretical, conceptual and methodological approaches in the context of LMICs. In fact, a review of writings (1933-2003) concerning research on the implementation of public policies shows that only $4 \%$ concerned Africa, 2\% Latin America and $15 \%$ was on health. ${ }^{9}$ The author of this review clearly highlighted 'the ethnocentric bias in implementation studies'. ${ }^{9}$ This observation was confirmed in another analysis (1986-2006) of research in public policies in the field of health promotion: 'all the most authoritative conceptualizations mentioned here were modelled on Western-style democratic governance systems' ${ }^{10}$ Two rapid bibliographic searches using Pubmed database show an important increase of papers about global health and implementation since 1970, but implementation still concern just around $5 \%$ (figure 1). Therefore, there is an urgency to act, since both analyses confirm that we are far from having a body of theories, frameworks and approaches which is sufficient for the in-depth study of the implementation of interventions; ${ }^{9} 1112$ interventions which still need to be largely 'tested and operationalised in real-world settings'. ${ }^{13}$ 


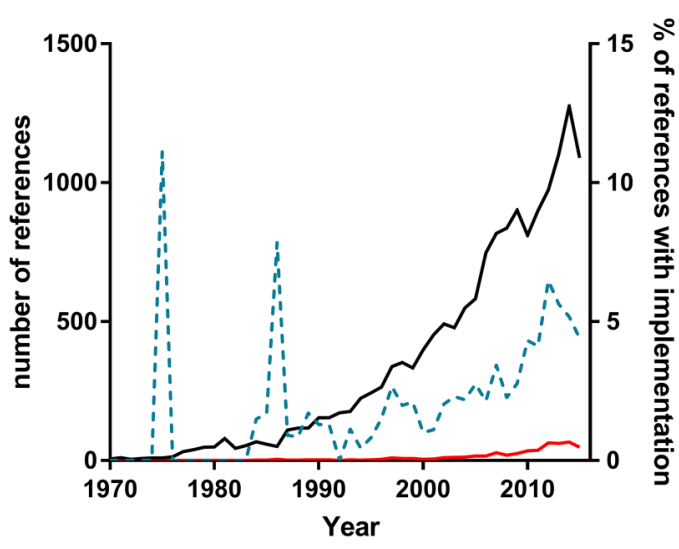

Figure 1 Global health and implementation science papers from 1970 to 2015. Two rapid bibliographic searches using PubMed database were performed. Search 1, in order to obtain all references about global health, the following was used: [Global health (MeSH, major topic) OR international health (title / abstract)], given that the MeSH term was introduced only recently. In order to exclude interventions studies about pharmaceutical treatment, the following terms were added: NOT [pharmaceutic (Title/Abstract) OR drug (Title/Abstract) OR vaccine (Title/Abstract)]. Results of search 1 are presented with the black line (left axis) per year since 1970. Search 2, in order to extract in these results, studies focusing on implementation science, the following terms were added: AND [implementation (Title/Abstract)]. Results of search 2 are presented with the red line (left axis) per year since 1970. In the blue dotted line (right axis) the calculated percentage of references focusing on implementation science (search 2) in the global health area of research (search 1). Data analysis performed by Stéphanie Degroote.

This urgency should not be taken lightly. It is important that implementation studies in LMICs adhere to what is often called the third generation, which uses more rigorous research design. ${ }^{44}$ While global health actors appear to have discovered implementation science recently, ${ }^{15}$ it was actually mobilised at least more than 30 years ago by political science researchers. ${ }^{9}$ It is not necessary in this editorial to discuss the history of the analysis of intervention implementation ${ }^{8} 911$ which should be better understood (and thus better taught ${ }^{16}$ ) and used by those who study implementation. However, research on global health implementation should better exploit the theories, conceptual frameworks and approaches of the social sciences. ${ }^{12}$ As essential as the inductive and empirical approaches may be, recourse or contribution to theoretical and conceptual development is as important, if not even more. ${ }^{17}$ As a reminder, among the health promotion studies which analysed public policy, only $18 \%$ made reference to a theoretical framework. ${ }^{18}$ Studies showed that Kingdon's stream theory $^{19}$ along with Lipsky's street-level bureaucrats ${ }^{20}$ and Rogers' innovation theory, ${ }^{21}$ which were all developed in the USA, could also have been adapted in the context of certain LMICs in order to better understand implementation. Additionally, the role of ideas in the implementation (rather than the emergence) of interventions in LMICs have not really been tackled, ${ }^{22}$ whereas the writings on high-income countries in this regard have been abundant. ${ }^{23}$

Implementation science clearly cannot be developed alone without considering the effects of interventions (or the principles of effectiveness, to borrow from Patton's words ${ }^{24}$ ), because it risks falling into 'type 3 error', where an intervention is evaluated even though it has not yet been implemented as anticipated. ${ }^{25}$ Thus it is important to better describe the content of interventions using available tools ${ }^{26} 27$ and to report on the (classic) fidelity and intensity of implementation. It is also necessary to update the adjustments of interventions-inevitable in a natural context-and the fidelity of the theory. ${ }^{28} 29$ It is in this contextual and holistic research approach that we should conduct and report implementation science. The recurrence of several types of interventions in many settings, the links between the effects (expected or not), the processes, the actors and their context should be brought to light, notably with the theoretical approach of critical realism, which is still not well-tested in LMICs. ${ }^{30}$ Critical theory could be used to better understand power relations. Individual relations and the role that context plays in the matter should be studied to understand, for example, the heterogeneity of effects in the implementation of interventions. ${ }^{31}$ When not forgotten, contextual analysis specifically associated with interventions is often the poor parent. ${ }^{32}$

The use and presentation of methods should also be considered in developing this field by making it more credible to those who think that qualitative research or the flexible approach to research design, ${ }^{33} 34$ which are integral parts of implementation science, are not rigorous enough. For this, it is necessary that authors are more precise in the description of their methods of qualitative sampling and of their analysis procedures. Beyond these interdisciplinary, boundary-spanning approaches, which are necessary in global health, ${ }^{35}{ }^{36}$ the recourse to mixed methods and to multiple case studies, if longitudinally possible, would be a major benefit for implementation science. ${ }^{14}$

It is certainly time to seriously consider the charge which was made almost 10 years ago on policy research in LMICs: 'more work on implementation, and specifically, the challenges of implementing equity-oriented policies, as well as more examination of successful policy change experiences'. ${ }^{37}$ We invite authors to participate in this by proposing and submitting implementation science articles to BMJ Global Health.

Acknowledgements The author would like to thank Loubna Belaid, Lara Gautier, Omar Samb and Anne-Marie Turcotte-Tremblay for their feedback on a previous version of this article and Stéphanie Degroote for the data analysis in figure 1.

Funding VR holds a CIHR-funded Research Chair in Applied Public Health (CPP-137901). They also acknowledge Mary Londres for translation and editing support and Seye Abimbola for editing support of this editorial. 
Competing interests VR is a BMJ Global Health Associate Editor.

Provenance and peer review Commissioned; internally peer reviewed.

Data sharing statement No additional data are available.

Open Access This is an Open Access article distributed in accordance with the Creative Commons Attribution Non Commercial (CC BY-NC 4.0) license, which permits others to distribute, remix, adapt, build upon this work noncommercially, and license their derivative works on different terms, provided the original work is properly cited and the use is non-commercial. See: http:// creativecommons.org/licenses/by-nc/4.0/

\section{REFERENCES}

1. United Nations Secretary-General. Global strategy for women's and children's health. New York: United Nations, 2010.

2. CSDH. Closing the gap in a generation: health equity through action on the social determinants of health. Final Report of the Commission on Social Determinants of Health. Geneva, World Health Organization, 2008. http://apps.who.int/iris/bitstream/10665/43943/1/ 9789241563703 eng.pdf

3. Peters DH, El-Saharty S, Siadat B, et al. eds. Improving health service delivery in developing countries from evidence to action. Washington: World Bank, 2009.

4. Durlak JA, DuPre EP. Implementation matters: a review of research on the influence of implementation on program outcomes and the factors affecting implementation. Am J Community Psychol 2008;41:327-50.

5. Durlak JA. Studying program implementation is not easy but it is essential. Prev Sci 2015;16:1123-7.

6. Peters DH, Tran NT, Adam T. Implementation research in health: a practical guide. Geneva: World Health Organization. Alliance for Health Policy and Systems Research, 2013.

7. Siron S, Dagenais C, Ridde V. What research tells us about knowledge transfer strategies to improve public health in low-income countries: a scoping review. Int J Public Health 2015;60:849-63.

8. Nilsen P, Ståhl C, Roback K, et al. Never the twain shall meet?-a comparison of implementation science and policy implementation research. Implement Sci 2013;8:63.

9. Saetren $\mathrm{H}$. Facts and myths about research on public policy implementation: out-of-fashion, allegedly dead, but still very much alive and relevant. Policy Stud J 2005;33:559-82.

10. Breton $E$, De Leeuw $E$. Theories of the policy process in health promotion research: a review. Health Promot Int 2011;26:82-90.

11. Fischer F, Miller G, Sidney MS, eds. Handbook of public policy analysis: theory, politics, and methods. Boca Raton: CRC/Taylor \& Francis, 2007

12. Durlak JA. What everyone should know about implementation. In: Durlak JA, Domitrovich CE, Weissberg RP, Gullotta TP, eds. Handbook of social and emotional learning: research and practice New York: The Guilford Press, 2015:395-405.

13. Franks B, Schroeder J. Implementation science: what do we know and where do we go from here? In: Halle T, Metz A, Martinez-Beck I, eds. Applying implementation science in early childhood programs and systems Baltimore: Paul H. Brookes Pub. Co, 2013:5-21.

14. Saetren $\mathrm{H}$. Implementing the third generation research paradigm in policy implementation research: an empirical assessment. Public Policy Adm 2014;29:84-105.

15. Madon T, Hofman KJ, Kupfer L, et al. Public health. Implementation science. Science 2007;318:1728-9.
16. Ghaffar A, Gilson L, Tomson G, et al. Where is the policy in health policy and systems research agenda? Bull World Health Organ 2016;94:306-8.

17. Olivier de Sardan JP, Ridde V. Public policies and health systems in Sahelian Africa: theoretical context and empirical specificity. BMC Health Serv Res 2015;15:S3.

18. Breton E, Richard L, Gagnon F et al. Health promotion research and practice require sound policy analysis models: the case of Quebec's Tobacco Act. Soc Sci Med 2008;67:1679-89.

19. Ridde V. Policy implementation in an African State: an extension of the Kingdon's multiple-streams approach. Public Adm 2009;87:938-54.

20. Walt G, Shiffman J, Schneider $\mathrm{H}$, et al. 'Doing' health policy analysis: methodological and conceptual reflections and challenges. Health Policy Plan 2008;23:308-17.

21. Perez D, Lefevre $\mathrm{P}$, Castro $\mathrm{M}$, et al. Diffusion of community empowerment strategies for Aedes aegypti control in Cuba: a muddling through experience. Soc Sci Med 2013;84:44-52.

22. Béland D, Ridde V. Ideas and Policy Implementation: understanding the resistance against Free Health Care in Africa. Glob Health Gov 2016. In Press.

23. Béland $\mathrm{D}$, Cox $\mathrm{RH}$, eds. Ideas and politics in social science research. New York: Oxford University Press, 2011.

24. Patton MQ. Developmental evaluation: applying complexity concepts to enhance innovation and use. The Guilford Press, 2010.

25. Dobson D, Cook TD. Avoiding type III error in program evaluation: results from a field experiment. Eval Program Plann 1980;3:269-76.

26. Hoffmann TC, Glasziou PP, Boutron I, et al. Better reporting of interventions: template for intervention description and replication (TIDieR) checklist and guide. BMJ 2014;348:g1687.

27. Hales S, Lesher-Trevino A, Ford N, et al. Reporting guidelines for implementation and operational research. Bull World Health Organ 2016;94:58-64.

28. Pérez D, Van der Stuyft $P$, Zabala MC et al. A modified theoretical framework to assess implementation fidelity of adaptive public health interventions. Implement Sci 2015;11:91.

29. Hawe P, Shiell A, Riley T. Theorising interventions as events in systems. Am J Community Psychol 2009;43:267-76.

30. Kwamie A, van Dijk H, Agyepong IA. Advancing the application of systems thinking in health: realist evaluation of the Leadership Development Programme for district manager decision-making in Ghana. Health Res Policy Syst 2014;12:29.

31. Belaid L, Ridde V. Contextual factors as a key to understanding the heterogeneity of effects of a maternal health policy in Burkina Faso? Health Policy Plan 2015;30:309-21.

32. Shoveller J, Viehbeck S, Di Ruggiero E, et al. A critical examination of representations of context within research on population health interventions. Crit Public Health 2015:1-14.

33. Robson C. Real world research : a resource for users of social research methods in applied settings. 3rd edn. Chichester, West Sussex: Wiley, 2011.

34. Olivier de Sardan JP. Epistemology, fieldwork, and anthropology London: Palgrave, 2015.

35. Ridde V, Olivier de Sardan JP. La mise en oeuvre des interventions de santé publique en Afrique: un thème stratégique négligé. Médecine Santé Trop, 2016.

36. Sheikh K, Schneider H, Agyepong IA, et al. Boundary-spanning: reflections on the practices and principles of Global Health. BMJ Glob Health 2016;1:e000058.

37. Gilson L, Raphaely N. The terrain of health policy analysis in low and middle income countries: a review of published literature 19942007. Health Policy Plan 2008;23:294-307. 